\title{
The Attitude of Non-Government Primary School's Authority Toward Inclusive Education in Bangladesh
}

\author{
Asma Islam ${ }^{1, ~ *, ~ S u l t a n a ~ N a s r e e n ~}{ }^{2}$, Zakia Islam $^{3}$, Nabila Ahmed ${ }^{4}$, Sadia Islam $^{3}$ \\ ${ }^{1}$ Department of Physiotherapy, Bangladesh Health Professions Institute (BHPI), CRP, Savar, Dhaka, Bangladesh \\ ${ }^{2}$ Bangladesh Health Professions Institute (BHPI), CRP, Savar, Dhaka, Bangladesh \\ ${ }^{3}$ Angelica International School, Savar, Dhaka, Bangladesh \\ ${ }^{4}$ Apple Tree International School, Dhaka, Bangladesh
}

Email address:

asmaphysio@gmail.com (A. Islam), bhpinasreen@yahoo.com (S. Nasreen), zakiyah.munia@gmail.com (Z. Islam), Nabila2004nepa@yahoo.com (N. Ahmed), tumpasadia63@gmail.com (S. Islam)

${ }^{*}$ Corresponding author

\section{To cite this article:}

Asma Islam, Sultana Nasreen, Zakia Islam, Nabila Ahmed, Sadia Islam. The Attitude of Non-Government Primary School's Authority Toward Inclusive Education in Bangladesh. International Journal of Elementary Education. Vol. 10, No. 1, 2021, pp. 16-20. doi: $10.11648 /$ j.ijeedu.20211001.12

Received: October 17, 2020; Accepted: November 30, 2020; Published: March 17, 2021

\begin{abstract}
Introduction; Inclusive education has introduced and got special attention for the last few years in Bangladesh. Bangladesh is the country that emphasized the global agreement that protects the rights of children with disabilities. The Country has also taken several legislative and policy actions towards nationalizing these global commitments such as the Right to quality education to children with disabilities. The private schools of this country accommodate a big number of children and are not aware of the policy therefore it is important to explore the existing situation. Aim; the study aimed to find out the attitude of primary school authority about the inclusion of children with disabilities in their mainstream of the system. Method; Thirty NonGovernments Primary schools were selected conveniently which were situated in a different part of Dhaka city. A semi-structured questionnaire was developed and given to the school authority. The collected data analyzed qualitatively and presented in a narrative format. Result and discussion; Most of the school authority showed a positive attitude towards inclusion but they also identified several barriers predominantly the lack of physical accessibility and trained teachers. Conclusion and Recommendation; As Private schools are accommodating a massive amount of students in Bangladesh for education, it is very important to have an inclusive schooling system for special needs children in those private schools. The study found most of the school authorities have a positive attitude. Therefore, the Government and Nongovernment help is required.
\end{abstract}

Keywords: Children with a Disability, Inclusive Education, Attitude

\section{Introduction}

Bangladesh has been developed in reducing poverty, maternal mortality, child mortality, and malnutrition since the last few decades as a part of the Millennium Development Goal (MDG) [1]. There is also an increase in enrolment in primary school without gender discrimination. Despite this, we are often confused about the children with disability. The children who have or vulnerable to have the chronic physical, developmental, behavioral, or emotional condition and need special health intervention are considered as the Children with special health care needs or Children with disabilities [2].
Another literature suggests Child with disability are those who have mental retardation, hearing impairment, speech or language impairment, visual impairment, serious emotional disturbance, orthopedic impairment, autism, traumatic brain injury, other health impairment, specific learning disability, deaf-blindness, or multiple disabilities and they require special education and related service [3]. People with disability including children are often exposed to disparity towards the mainstream developmental process. They stay behind due to various social, cultural, and economic barriers. This discrimination is not only for the physical impairment but also the prejudice and discriminating attitude of the society [1]. 
Disabled girls and rural children are additionally discriminated against. They are considered as a curse, a matter of shame therefore hidden form the entire society [4]. Education for the disabled so far in Bangladesh is isolated in special needs schools where inclusive schools are rarely seen both in Government and Non-government education system. Inclusive Education as defined in the UNESCO Salamanca Statement June 1994 that inclusive education is the education system where it ensures education for all. Inclusive education is also based on a child-centered approach that is capable of successfully educating all children, including those who have serious disadvantages and disabilities. The merit of such schools is not only that they are capable of providing quality education to all children but their establishment is a crucial step in helping to change discriminatory attitudes, in creating welcoming communities, and in developing an inclusive society [5]. There are some global agreements where it is mentioned that it is the right of all children including the disabled to educate equally [6]. The government of the People's Republic of Bangladesh had been emphasized the important global agreements related to protecting the right of children with disabilities for many years. According to The Bangladesh Primary Education (Compulsory), Act 1990 Primary education is free for all from grades one through five. It is the law that the children between the ages of six and ten must attend school [7]. There were some further policies established such as the National Children's Policy (1994), the Operational Framework for Pre-primary Education (2008), the National Programme of Action for Children (2004-2009), the Child Act 2013, and the Comprehensive Early Childhood Care and Development Policy (2013). This framework was linked to the Education for All: National Plan of Action for Children II (2003-2015), the National Children Policy (2011), the National Education Policy (2010), and the Education Act (2013). Recently some significant initiatives on primary education were taken through the Second Primary Education Development Programme (PEDP-II) in 2003-2011 and Third Primary Education Development Programme (PEDP-111) in (2011-2017) and address inclusive education and they developed a framework to device the different parameters of inclusive education through several consultative workshops between government and non-government organizations. Under these policies inclusion of a diverse group of children such as disable, ethnic community children, and other vulnerable groups of children inclusion was mandatory [8]. In recent years the primary school age enrollment rates increased by up to 89 percent of boys and 94 percent of girls. But unfortunately, some children such as working children, disabled, indigenous, the children who are living in a remote area, and extremely poor family children are facing a challenge and remain ignored [9]. Therefore, all professionals must abide by the national policy. As a rehabilitation expert, it is experienced that policy, legislation always cannot bring desired change unless there are awareness, a positive attitude, and proper practice. So it is a vital issue to explore the community attitudes and the interest has been created to find out the existing situation regarding the attitude of the school authority towards the inclusion of the children with disabilities in the mainstream of education.

\section{Material and Method}

A Semi-structured questionnaire was developed aiming to find out the existing knowledge of the school's authority about children with disabilities and their education rights. It was also intended to find their willingness in the inclusion of the Children with a disability at their school, the barriers they might face, and finally to find out some recommendations from them that might be useful in the inclusion of the disabled children in the private sector. 30 non- government Primary schools were selected conveniently which were situated in a different part of Dhaka city of Bangladesh from July 2018 to December 2018. The researcher met the school authority and explained the situation, aim, objectives. All the participants were the Principal of the school. The written consent and a questionnaire were given to them. The collected data was analyzed qualitatively which explored several themes that were further described and presented in a narrative format. After interviewing thirty schools the data showed a similar approximation that imposed to discontinue further inquiry.

\section{Result}

The schools accommodated the number of students ranging from 500 to 2500 . All of them were situated in the residential rental building which was in the residential area. Few of them were in the multistoried building where most of them were on the ground floor. Only a few were having a playground in front of the school. The achieved groups of data analysis revealed several themes that are discussed below.

Table 1. The result at a glance.

\begin{tabular}{|c|c|}
\hline Theme & Findings \\
\hline Theme one & Most of the schools did not have any disabled children. Very Few Schools accommodated disabled children. \\
\hline Theme two & Most of them Showed a positive attitude towards the Inclusion of Physically Disabling Children. \\
\hline Theme three & Children with Disabilities are addressed "Autistic Child” by them. \\
\hline Theme four & None of the Schools had a Disabled-friendly Environment \\
\hline Theme five & Most of them do not have any Idea about universal design for the school setting. \\
\hline Theme six & Most of them are aware of The Education Right of Disabled Children. \\
\hline Theme seven & $\begin{array}{l}\text { The barriers that have been identified are the social negative attitude, Inferiority Complex of Disable Children's Family, lack of trained } \\
\text { teacher, infrastructure of Schools and Education Cost. }\end{array}$ \\
\hline Theme eight & $\begin{array}{l}\text { To overcome the barriers, they marked the change of Social Attitude, Government support, and support of the rich people of the society, } \\
\text { positive attitude of the parent of disabled children, special school, Infrastructure change, and funding as important actions. }\end{array}$ \\
\hline Theme nine & Most of them suggested to have specialized schools rather than Inclusive schools in the private sector. \\
\hline
\end{tabular}




\subsection{Theme One}

\section{Very Few Schools Have Disabled Children}

Most of the schools did not have any disabled children. Only four schools had physically disabled children. Each school of the four had one disabled child therefore only 4 were found from 30 schools which is significantly less. They mentioned that they intentionally used to avoid admitting them. In some schools after admission, they even canceled the admission of the disabled child for their inconvenience. Many of them prefer physically disabled children rather than mental, visual, auditory, and others.

\subsection{Theme Two}

Most of Them Showed a Positive Attitude Towards the Inclusion of Physically Disabling Children.

Most of the school authorities showed a very positive attitude towards the inclusion of disabled children in their schools. They think that Disabled children should have an equal right to education. But they also mentioned that due to their environmental limitation they are unable to include them. Some of them said that they used to call them differently able rather than disable. One of them said that normal children will learn from disabled children and they will be more thankful and happy to be a normal one. One of them told that the empathy of the teacher and the normal students will increase toward the disabled children.

\subsection{Theme Three}

Children with Disabilities Are Addressed "Autistic Child"

Any kind of disability is considered as Autism among the school authority. Most of them pronounced the word "Autistic child" for any kind of disability. The term "Autistic child" seemed to be a very popular and known term to identify any kind of disability.

\subsection{Theme Four}

None of the Schools Had a Disabled-friendly Environment As most of the schools were situated in residential buildings, they didn't have enough space, ram, Elevator, Wide door, High commode toilet. The roads of the schools were severely damaged which caused great difficulty even for the normal children to reach the schools.

\subsection{Theme Five}

Most of Them Do Not Have Any Idea About Universal Design for the School Setting

Almost all of them were unaware of the special environmental facilities such as Ram, Elevator, Wider doors, wider space, and high commode in the toilet which are required for disabled children. When the idea of universal design was shared they express that this may not be possible to arrange. Some of them said it is impossible to arrange.

\subsection{Theme Six}

Most of Them Are Aware of the Education Right of Disabled Children

Many of them claimed that they are aware of the education right of disabled children. They said that the Government rules are suitable for Government schools. It is difficult for them to follow the government instructions as they identified several barriers especially the environmental barriers.

\subsection{Theme Seven}

The barriers that Have Been Identified Are the Social Attitude, Inferiority Complex of Disable Children's Family, Lack of Trained Teacher, Infrastructure of Schools, and Education Cost.

Most of them claimed that the parent of disabled children feels shy to expose their children to the entire society. They don't even themselves are unwilling to admit their children. Only, for this reason, many disabled children remain uneducated. Sometimes teachers and parents of normal children have the stigma that their child may become disabled if they are in the same school. Some parents anticipate that their children could mimic them and might develop bad habits. Some teachers feel very disturbed to pay special attention and effort. The normal students often tease them which worsen the situation for the disabled children and their family. The parent of normal children also shows a negative attitude. Moreover, they mentioned that although they are very positive toward the inclusion of disabled children, they have to lack specially educated or trained teachers. Moreover, there are no specific guidelines for the government for private schools. They feel that they have no special environmental arrangement for disabled children as most of them are in the rented pre-structured building. If they want to reconstruct the building it will be expensive which is not possible for them.

\subsection{Theme Eight}

To Overcome the Barriers, they marked the change of Social Attitude, Government support, and support of the rich people of the society, Attitude of the parent of disabled children, special school, Infrastructure change, and Funding as the important actions.

Almost all of them told that the attitude of society should be changed. The parent of disabled children should be more aware of education. They said that the government should have a specific guideline for the non-government school as well. The school authority should aware of the education right of disabled children and should include some disabled children in their school. They should have the least environmental setting for the accessibility of disabled children. As it is an expensive process, the rich people of the society, parents of non-disabled children, and the Government should help them. 


\subsection{Theme Nine}

Most of them suggested to have Specialized school rather than Inclusive schools in the private sector.

Some of them suggested establishing several specialized schools in every area of Bangladesh rather inclusive schools in the private sector as a logical step. As the infrastructure and the expense is the key barriers, the specialized school can be preplanned, structured, recruited trained professionals, therefore, would be good enough to serve the special demand of the disabled children. They mentioned that rich people of society can be a respected investor.

\section{Discussion}

An attitude is "a relatively enduring organization of beliefs, feelings, and behavioral tendencies towards socially significant objects, groups, events or symbols" [10]. It is changeable by communication, the behavior of other people or social influence, and individual motivation [11]. The attitude and environmental barriers are the key disabling and impairing factors rather than the disability itself. The children with disabilities are generally ignored and get the least or no service, vulnerable to be the victim of social and familial violence compared to non-disabled peers. They are often kept in alternative care rather than reside in their own family which causes further discrimination. Thus Stigma, ignorance, neglect, superstition, and communication barriers are the social factors that are responsible for exclusion from society [12]. The conducted study also found a similar picture of our society. It revealed a mixed attitude mostly positive attitude among the school authority towards the inclusion of the disabled children. At the same time, they have identified many barriers which were described by them as an unavoidable and almost impossible to overcome. Such as the external features: Space, accessibility, lack of universal design, and so on. They also mentioned the different types of disability and their interest. Many of them preferred to include physically disabled children rather mentally disabled, visual, auditory, and others. They highly recommended establishing specialized schools rather the inclusive school, especially in the private sector. But at the same time, they were positive towards the inclusion of the specific type of disable children such as some sort of physically disabled according to their existing capability. Some other studies found similar findings in different settings. A study by was conducted on Attitudes towards inclusive education and dimensions of the teacher's personality. They found that $80 \%$ of the teachers have supported the idea of inclusive education. They preferred to include physically challenged and the children with emotional difficulty than any chronically diseased children. They had the strongest avoidance of the children with an attention disorder, speaking disorder writing disorder, behavioral disorder [13]. Another study revealed a variety of attitudes in the different age groups of teachers regarding the knowledge of main concepts of inclusion. More experienced, previously experienced with disable children, highly educated teachers are more positive towards inclusion [14]. a study on Teachers' attitudes towards inclusion of students with intellectual disability in Bosnia and Herzegovina have found that $50 \%$ of the teachers support the concept of inclusion but they expressed that they are not supported enough to efficiently deal with the issue of inclusion [15]. Another study on Factors Associated with Primary School Teachers' Attitudes towards the Inclusion of Students with Disabilities found that male teachers, teachers over 55 years, teachers with low levels of self-efficacy in their skill showed negative attitude whereas the teachers having special training for dealing with disabled children showed a positive attitude [16]. A study was conducted in Finland among basic-school teachers where they found that special education teachers retain more positive attitude than the subject or class teachers [17]. A study in Ghana explored that subjective norms and self-efficacy are the strong predictors for the intention of secondary school teachers towards practicing inclusive education [18]. Another study found that preschool and primary school teachers have more positive attitude towards the inclusive education in Slovenian school teachers [19]. It is very important to focus on the above mentioned determinants which were found from different scientific literature to change the attitude and better inclusion of the children with disability in the mainstream of education. Government of Republic of Bangladesh need to have a prompt concentration in this area.

\section{Conclusion}

The objective of the study was identified and successfully able to find the existing knowledge about inclusive education, the willingness of the school authority towards the inclusion, barriers faced by them, and finally the recommendation of them. Most of the school authorities had a very clear idea about inclusive education. They were also very cooperative to share their ideas. They were also showed enough interest to include disabled children; in fact, some schools already had some disabled children though the number was significantly less. They mentioned that the physical environment of the school is the major area of challenge. As the study explored mostly the positive attitude among the school authority, there is a great chance for the rehabilitation experts to motivate them further and help them to overcome the barriers. The Government and Non-government organizations, therefore, can play a great role in this expectant area.

\section{Acknowledgements}

We would like to acknowledge the school's authority, study supervisor, and our academic institute for giving us the opportunity, guidance, and cooperation to do this study.

\section{Declaration of Interest Statement}

We are declaring that this piece of study is only submitted 
to this journal for the first time. The authors declare no conflict of interest.

\section{Funding}

The study was conducted entirely by the personal funding of researchers.

\section{References}

[1] UNICEF. (2014, March). Situation Analysis on Children with Disabilities in Bangladesh. (Weblog). Retrieved 14 December 2017 , from https://www.unicef.org/bangladesh/knowledgecentre_9023.ht $\mathrm{ml}$

[2] McPherson M, Arango P, Fox H, Lauver C, McManus M, Newacheck PW, Perrin JM, Shonkoff JP, Strickland B. A new definition of children with special health care needs. Pediatrics. 1998 Jul 1; 102 (1): 137-9.

[3] Idea. (2017). Idea partnership org. Retrieved 20 December, 2017, from http://www.ideapartnership.org/topicsdatabase/idea-2004/idea-2004-part-b/1396-definition-of-childwith-a-disability.html

[4] Nahar, L. (2016). An Analysis of the Disabled Children's Right to Education In Bangladesh. Law journal Bangladesh, 4.

[5] UNICEF. (2012). The Right of Children with Disabilities to Education: A Rights-Based Approach to Inclusive Education. Retrieved 1 January, 2018, from https://www.unicef.org/eca/education_18613.html

[6] Peters SJ. Inclusive education: An EFA strategy for all children. Washington, DC: World Bank, Human Development Network; 2004 Nov 1.

[7] Ministry of Primary and Mass Education, Bangladesh (n.d.). Retrieved 9 November, 2019, from https://mopme.gov.bd/accessed 9/11/2019

[8] Malak M. Inclusive Education in Bangladesh: Policy and Practice. Australian Association for Research in Education. 2013.
[9] Siddique, N. (2008). UNICEF Bangladesh. Retrieved 17 December, 2017, from https://www.unicef.org/bangladesh/children 4861.html

[10] Hogg, M., \& Vaughan, G. (2005). Social Psychology (4th edition). London: Prentice-Hall.

[11] Wikipedia the free encyclopedia. (n.d). Attitude change. Retrieved 7 January, 2018, from https://en.wikipedia.org/wiki/Attitude_change

[12] UNICEF for every child. (2012). Changing attitudes towards people with disabilities. Retrieved 7 January, 2018, from https://www.unicef.org/protection/index_66543.html

[13] Todorovic et al. (2011). Attitudes towards inclusive education and dimensions of teacher's personality. Procedia - Social and Behavioral Sciences 29 (2011), 29 (1), 426 - 432. Retrieved 1 January, 2018, from http://dx.doi.org/10.1016/j.sbspro.2011.11.259

[14] Unianu EM. Teachers' attitudes towards inclusive education. Procedia-Social and Behavioral Sciences. 2012 Jan 1; 33: 9004. doi.org/10.1016/j.sbspro.2012.01.252.

[15] Memisevic, H \& Hodzic, S. (2011). Teachers' attitudes towards inclusion of students with intellectual disability in Bosnia and Herzegovina. International Journal of Inclusive Education. 15, 699-710. doi.org/10.1080/13603110903184001.

[16] Vaz S, Wilson N, Falkmer M, Sim A, Scott M, Cordier R, Falkmer T. Factors associated with primary school teachers' attitudes towards the inclusion of students with disabilities. PloS one. 2015 Aug 28; 10 (8): e0137002. doi.org/10.1371/journal.pone.0137002.

[17] Saloviita, T. (2020). Attitudes of teachers towards inclusive education in Finland. Scandinavian Journal of Educational Research, 64 (2), 270-282.

[18] Opoku, M. P., Cuskelly, M., Pedersen, S. J., \& Rayner, C. S. (2020). Attitudes and self-efficacy as significant predictors of intention of secondary school teachers towards the implementation of inclusive education in Ghana. European Journal of Psychology of Education, 1-19.

[19] Štemberger, T., \& Kiswarday, V. R. (2018). Attitude towards inclusive education: the perspective of Slovenian preschool and primary school teachers. European Journal of Special Needs Education, 33 (1), 47-58. 